\title{
Factors Affecting on Gaining a Sustainable Competitive Advantage for Sri Lankan Higher Educational Institutes
}

\author{
Liyanachchi Mahesha Harshani De Silva ${ }^{1}$, Charith D. Chitraranjan ${ }^{2}$ \\ ${ }^{1}$ Assistant Lecturer, Department of Business Management, Faculty of Business, Sri Lanka Institute of \\ Information Technology, Sri Lanka \\ ${ }^{2}$ Department of Computer Science and Engineering, University of Moratuwa, Sri Lanka \\ Correspondence: Liyanachchi Mahesha Harshani De Silva, Assistant Lecturer, Department of Business \\ Management, Faculty of Business, Sri Lanka Institute of Information Technology, Sri Lanka
}

Received: February 7, 2018

doi:10.5539/ibr.v11n4p106
Accepted: March 5, 2018

Online Published: March 12, 2018

URL: https://doi.org/10.5539/ibr.v11n4p106

\begin{abstract}
Over the past few years, number of seats has grown significantly in Higher Education Institutes (HEI), thus it becomes prudent to look at the ways of improving decision making of the HEI. Thus, the aim of this study is to investigate factors affecting the sustainable competitive advantage. Since literature does not support strong underpinnings in this area, an exploratory and grounded theory-based study was designed to conduct this study. The main contribution of this research is that we propose factors to consider for an HEI to achieve sustainable competitive advantage. Our findings indicate that proper student-teacher relationship, maintaining good reputation, maintaining a high rank and good indexing's, maintain good relationships with industries, student participation in competitions, accreditation from reputable institutions are the most significant factors affecting the sustainable competitive advantage (AA) within Sri Lankan HEIs. To remain competitive and obtain competitive advantages, HEI decision makers can try to increase organizational performance by managing each dimension of core competence, i.e. Market profile; Innovation and Core Competencies.
\end{abstract}

Keywords: sustainable competitive advantage, grounded theory, higher education

\section{Introduction}

\subsection{Background}

More demanding customer base and global competition have led many organizations to look into new ways of achieving and retaining competitive advantage(Woodruff, 1997). Competitive advantage can be gained when an organization consistently outperforms other companies in the same industry. It gives the advantage of generating a greater value for the firm as well as shareholders. To be stronger with the advantage, the organization should gain a sustainable competitive advantage. However to achieve this, organizations should have the ability to compete in the volatile environment. This competitive advantage has defined in the literature as a way of producing superior methods and resources compared to competitors over a long period of time. The sustainability of competitive advantage can be gained based on three major characteristics of resources and capabilities: "Durability; which is the period over which a competitive advantage is sustained, Transferability; the harder a resource is to transfer the more sustainable the competitive advantage is, and finally Replicability; whether it can be replicated or purchased from a market or not"(Sadler, 1993).

Most of the organizations and markets operating in extremely competitive environments have accepted that their competitive advantages are no longer sustainable(Schläfke, Silvi, \& Möller, 2012a). Therefore, new sources of competitive advantage are created, while others rapidly erode. Similar to business organizations, higher educational institutes have also been facing fierce competition in recent years due to the high demand for education worldwide. Thus, HEI should improve their decision-making process to achieve competitive advantage by increasing the efficiency and effectiveness. Sustainable competitive advantage within HEI is a contentious concept over decades but unfortunately, achievement has not been discovered as fast as expected due to the lack of understanding related to sustainability especially, in the Sri Lankan context.

Currently, Sri Lankan universities are in a process of promoting and investigating the methods of enhancing student learning experience. However, there is a limited number of measures and performance indicators to 
guide decision-makers and practitioners of the HEI. Due to the intangible nature of the service, decision makers tend to ignore or overlook the quality factors over the marketing aspects. The increasing competition has led institutions to become more upbeat in their marketing but to be sustained in the economy there should be more than marketing tactics. Currently, there is a huge tendency of migrating students into international institutes due to the low facilities and recognition compared to international universities. Developed countries such as Canada, the USA, Australia and the UK are already in the process of marketing themselves to attract students from home and overseas for higher education. Therefore, as a developing country, it is necessary to build distinctive capabilities which are superior compared to the competitors in this market, not only within the country but also in the international market.

To date, less number of empirical research has been conducted in the area of sustainable competitive advantage (Ali, Asadi, Ga Sevi C, Jovanovi, \& Hatala, 2013). Particularly in the Sri Lankan context, no research has been conducted to our knowledge. Therefore, an appropriate guidance to assist HEIs in successful competitive advantage is of utmost importance. Therefore, this paper proposes an effective measurement tool to benchmark current pedagogical performance standards and monitor the progress and achievement of future implemented practices designed to enhance the sense of community experienced by the student cohort. The objective of this study is to address the following question;

- What are the factors that have a strong effect on the achievement of a sustainable competitive advantage for Sri Lankan higher educational institutes?

\section{Literature Review}

As a consequence of fierce competition, today many companies, not only higher education institutes, argued that their competitive advantage is not sustainable. According to a past research of competitive advantage, Barney has stressed that a firm possesses sustained competitive advantage when it adopts a strategy that is "not simultaneously being implemented by any current or potential competitors and when other firms are unable to duplicate the benefits of this strategy."(Barney, 1991). According to Mazrol, sustainability is defined as the ability to develop business strategies, which cannot be imitated by the competitors(Mazzarol \& Norman Soutar, 1999). According to prior research competitive advantages measured by traditional barriers-to-entry variables, other economic rent proxies, and control variables, past superior performance, and sustained market share. In HEI competitive advantage is measured by the image quality of the institutes, market profile, and the degree of forward integration into the export channel, quality of the staff, student-oriented innovative culture and effective use of Information Technology.

This competitiveness is not limited to the customers. It is also applicable for gaining scare resources as well. This has become an interesting area to discuss in HEIs due to the globalization and the growth of the educational customer base. Past studies have suggested that business process management is an enabler for a sustainable competitive advantage(Velazquez, Munguia, \& Sanchez, 2005). Scholars have stated that core competencies should be developed within the organization in order to gain a sustainable competitive advantage(Agha, Alrubaiee, \& Jamhour, 2011). The core competency can be defined as the knowledge of success or failures, an efficiency of operations, or positive responses to the challenges. Further, it suggested that core competencies are key ingredients for organizational success. Therefore, this factor can be considered as one of the indicators to achieve a sustainable competitive advantage(Agha et al., 2011).

According to the research of "A model of sustainable competitive advantage for education services" this advantage has derived from internal skills of the organization as below; 


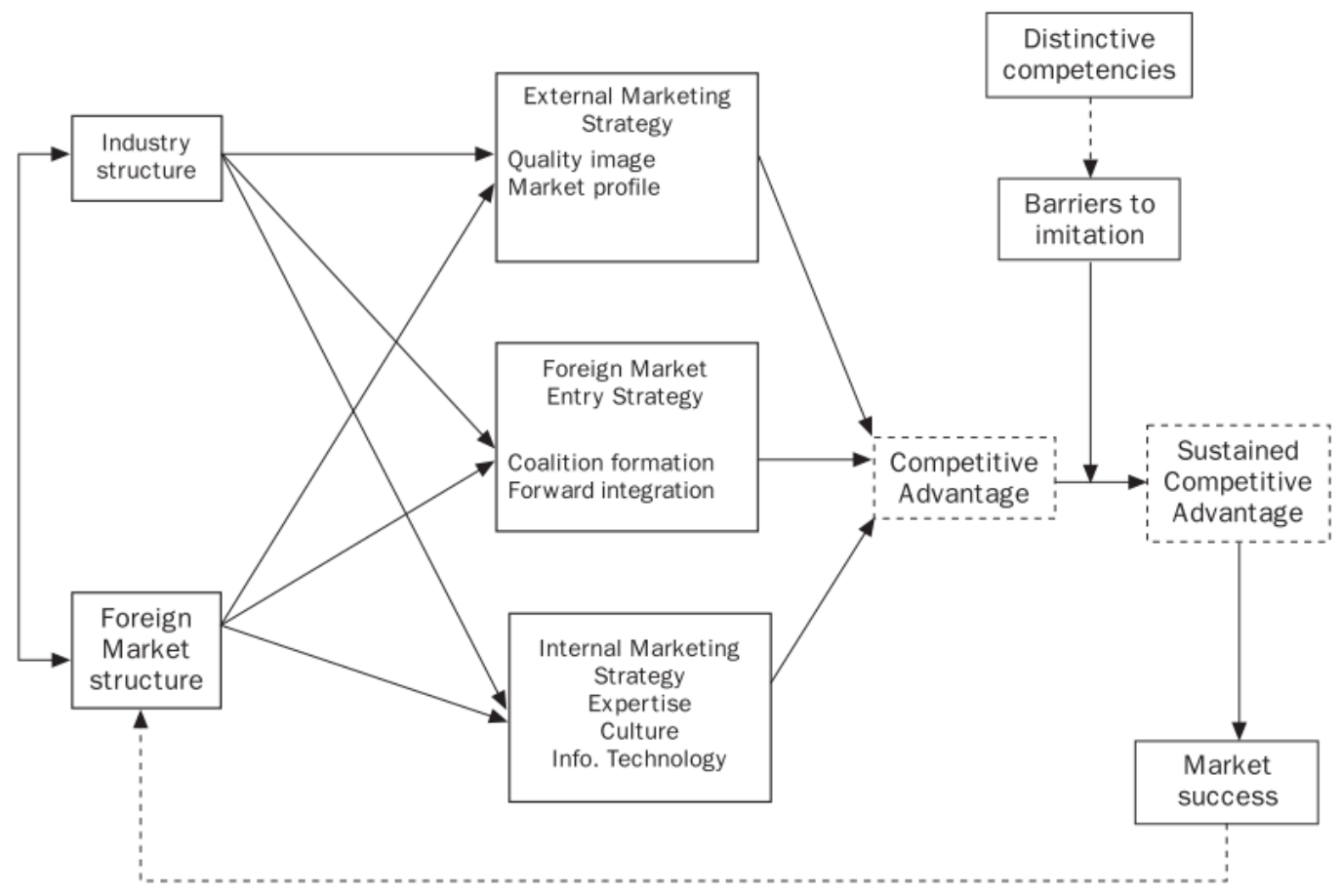

Figure 1. A model of sustainable competitive advantage for education markets

To bring the above discussed sustainability to HEI, it needs to focus at operational, managerial and strategic levels to gain a sustainable competitive advantage in this highly competitive markets(Schläfke, Silvi, \& Möller, 2012b).

Currently, there is a tendency of ignoring the sustainable competitive advantage within the HEI due to the intangible nature. The main concern of the HEI is to increase the number of students, but this has a chance of reducing the sustainable competitive advantage.

Theoretically, Theories of Competitiveness, Theory of the Resources and Capabilities, and Stakeholders Theory are the ways of achieving the sustainable competitive advantage in any business. Even-though developed countries align their strategies with above theories, Asian countries such as Sri Lanka have not focused adequately on those areas when conducting HEI decision-making activities.

\section{Methodology}

The main concern of this paper is to identify the factors affecting the sustainable competitive advantage in HEI. To construct the methodology, we have mainly focused on a qualitative and inductive approach. There are mainly two forms of research approaches described as inductive and deductive. In induction, the researcher observes and collects facts and develop a theory as a result of the data analysis. But deduction initiates with a theory in the field, and afterward, the researcher figures out hypothesis, which is tested in an empirical investigation(Sekaran, 2013). Further, the deduction can be explained as a method of deriving conclusions by interpreting the meaning of the results of the data analysis. As an examples, research has reviewed that increasing the stocks was positively correlated to customer satisfaction from their data analysis, then research can deduce that to increase the customer satisfaction, the shelves have to be better stocked. As explained in the literature review, inadequate research and attentiveness is evident in relation to business intelligence and strategic advantage of different industries. This led this research to use the inductive method.

Through a qualitative approach, using semi-structured interviews and grounded theory techniques, we explored the perspectives and concerns of fifteen stakeholders regarding the sustainable competitive advantage in Sri Lankan Higher Education Institutes.

Data analysis was conducted by transcribing all the interview recordings in full and uploading textual data into qualitative data analysis tool NVivo. Text and all the transcripts were reviewed and coded according to the objectives. Data unit was a sentence or a short paragraph based on the meaning.

Following table provides an overview of the participants selected for the interviews. This is the total population 
of the selected case study with regards to the objective of this study. The information in this summary table protects the anonymity of the participants.

Table 1. Grounded theory participants selected for the Study

\begin{tabular}{cllcll}
\hline$\#$ & Gender & Age & Education Level & Tenure & Position \\
\hline A & Male & $51-60$ & PhD & 5-10 years & Dean \\
B & Male & $51-60$ & PhD & 5-10 years & Dean \\
C & Male & $41-50$ & PhD & 2-5 years & Head \\
D & Male & $41-50$ & MSC & 5-10 years & Senior Lecturer \\
E & Male & $41-50$ & MSC & 5-10 years & Manager \\
F & Male & $41-50$ & PhD & 5-10 years & Manager \\
G & Male & $41-50$ & PhD & 5-10 years & Dean \\
H & Male & $41-50$ & MSC & 2-5 years & Manager \\
I & Male & $41-50$ & MSC & 2-5 years & Manager \\
J & Female & $41-50$ & PhD & 5-10 years & Head \\
K & Female & $41-50$ & PhD & 5-10 years & Head \\
L & Male & $41-50$ & Post-Doctoral & 5-10 years & Head \\
M & Male & $41-50$ & Post-Doctoral & 5-10 years & Head \\
N & Male & $41-50$ & MSC & 5-10 years & Head \\
O & Female & $41-51$ & MSC & 5-10 years & Head
\end{tabular}

After the interview sessions, further amplifications regarding the interview were made through follow-up phone calls, e-mail, and second interviews as well. The first step of the data analysis was to prepare a detailed description of the selected case-based company, based on interviews and supporting documentation. Therefore, the data collected from the first round of interviews were examined thoroughly using content analysis technique and constant comparison, which comes under the grounded theory technique. Content analysis is a qualitative systematic text analysis technique, which was developed twenty years ago in relation to social science(Elo \& Kyngäs, 2008). When using content analysis, the aim was to build a model to describe the phenomenon in a conceptual form. This study has merged grounded theory with the content analysis technique to acquire deep understanding within the identified context. In this study, to identify major themes (Dillon, 2012) the interviews data were cross-referenced with a properly coded mechanism. Furthermore, through the grounded theory mechanism, we tried to maintain the consistency between the variables and factors, which were identified during the interviews and literature. This technique encourages the emergence of a finding from the data set by constantly comparing incidents of codes with each other and then abstracting related codes to a higher conceptual level(Dillon, 2012).

Using the grounded theory mechanism, we examined the qualitative data thematically and ranked the identified themes by their frequency and later categorized them. The objective of the present research was to identify the factors affecting the sustainable competitive advantage.

First, open coding technique was used to identify the concepts, possible categories and related properties of the collected data. Identified concepts were organized into categories, then sub-categories were identified. Using the method of axial coding relationships were identified.

The category names were defined according to the names used by respondent's so-called indigenous terms. Further to make sense of data researcher were defined "so-called sensitizing" terms. After that, the first theoretical propositions were developed by drafting of memos. That is the point at which research insights were developed.

Once all the interview scripts were analyzed, using constant comparison method, data was reassessed and re-coded to identify the categories and properties. In each iteration, we tried to maintain the internal consistency of the structure of categories and properties, which were identified.

Once new concepts, which do not fit into the existing set of categories and properties occur then, again start questioning with additional interviews. These new interviews allowed further development and understanding of the categories, properties and their relationships.

The study was carried out several times through the data collection until the theoretical saturation point was reached. Lastly, the model grounded from the analysis was compared with the conceptual models previously reviewed in the literature, particularly the two models. The main intention of this method was to promote a final refinement of certain categories and properties because it allows maintaining the balance between learning from empirical data and existing theories without diminishing the value of an inductive approach.

Open coding is the preliminary step of the data analysis, the main idea is to collect data from a variety of sources such as interviews, documents or observations to develop categories and concepts. Those are the basic units of 
the research science grounded theory not concerning on prior theories. In this step, the researcher should code all the actions and important concepts related to the research question. In another way, research tries to break down the data into first level concepts, or master headings, and second-level categories, or subheadings. This is an iterative method to derive all the codes by comparing new codes with previous ones.

The whole coding process is iterative as follows;

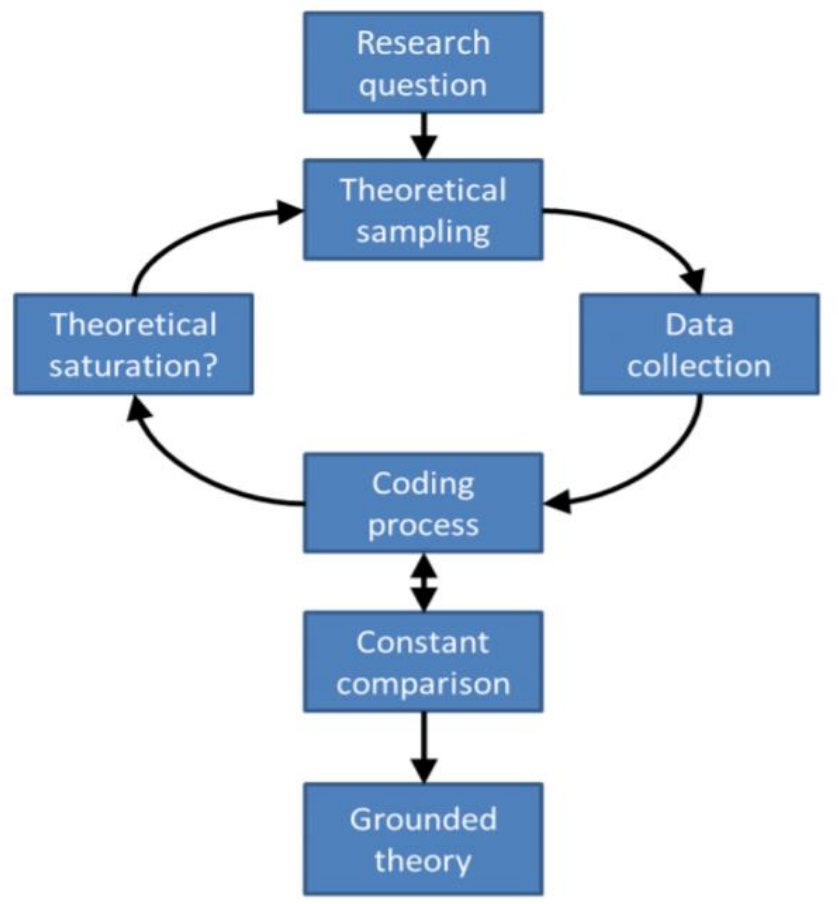

Figure 1. Grounded theory framework

Three coding types come under the coding process of the above figure.

With each interview transcript, we collected indicators such as words, phrases, statements from the data, or observations. In the following table, it provides an extensive list of the indicators collected from the 15 interviews. Open coding was able to conduct a thorough examination of the data, breaking it down into parts, making comparisons, and questioning. The indicators, then, are both identified bits of data collected and data that results from the process of breaking down the data.

Through axial coding, we were able to identify several themes as follows; this is the initial category of coding based on the proposed conceptual framework.

Factors affecting the sustainable competitive advantage in higher education.

\section{Findings and Discussion}

\subsection{Open Coding: Factors Affecting the Sustainable Competitive Advantage in Higher Education}

This is the first step according to the initial theme categorization of this research. Since this research does not base on the prior hypothesis, the study focused on the free responses provided by the participants of the interviews. For the first stage of factors affecting the sustainable competitive advantage in HEI, free responses presented as follows; this is not a one-time approach, iterative interviews were conducted to get a comprehensive idea about this topic. 
Table 2. Open Coding: Factors affecting to the sustainable competitive advantage in higher education

Factors affecting the sustainable competitive advantage in higher education

Person

Person A Interview Script

Can achieve a sustainable competitive advantage by being better or unique in education, by maintaining a good reputation, growing customer base, by maintaining recognizable name (brand), desirable market position, market-oriented curricula, producing quality market ready students, having accreditations. Currently, our organization has UGC approval and IET accreditation. Industry participation.

Person B Develop well maintained competent faculties including by recruiting top-level reputable professors who possess effective international network and rich experiential knowledge. Maintaining good rankings are necessary.

Person C To achieve sustainable competitive advantage university should acquire attributes, such as being better or unique, good reputation, growing customer base, recognizable name, desirable market position, market-oriented curricula, producing quality market ready students, engaging competent faculties including top-level reputable professors, possessing an effective international network and rich experiential knowledge.

Person D Developing a sustainable competitive advantage requires customer loyalty, a great location, unique merchandise such as curriculum of the courses, proper distribution channels, good vendor relations, good reputation based on the customer service, and multiple sources of advantage.

Person E To achieve the competitive advantage university should be able to produce highly competent and skilled graduates with experiential capability. Further, we can measure the competitive advantage by using some of the strategic frameworks such as Porter's competitive model, Resource-Based View of the Firm, Resource-Advantage (RA) theory, the Delta Model, Stakeholders Theory, and the Talent Management Model. Each respective model helps to answer some of the pertinent issues related to acquiring, gaining and maintaining a sustainable competitive advantage of the HEI.

Person F Building a good image before the society; students with appropriate preparation for the job market, performance evaluation, among others.

Person G To developing sustainable competitive advantage universities should maintain customer loyalty, a great location, proper curriculum, good reputation based on the customer service. Business intelligence can use to identify insights of the data and can use for decision making.

Person H Reputation and branding should improve in order to gain the sustainable competitive advantage.

Person I There are some theories which can use to achieve the competitive advantage such as Porter's theories of competitiveness (in the Industry and Territorial), the theory of the resources and capabilities (RBV), the Resource-Advantage (RA) theory, the Delta model, and the Stakeholders theory.

Person J Talent management best practices can use to recruit and retain the employees required to drive the organization's performance, and hence, success in providing quality service to students and customers.

Person K Carefully evaluate the challenges and threats of the environment, understanding the needs of the stakeholders, attracting and consolidating resources, facing the external changes and solving their internal problems.

Person $\mathbf{L} \quad$ Need to carefully understand the reasons regarding why students used to select a particular university. Further, need to maintain competent faculties with top-level reputable professors. Furthermore, the institute should maintain the excellence, reputation, status etc.

Person M Need to improve the understanding of the new types of higher education institutes which recently appeared at the Sri Lankan market in terms of virtual universities or corporate universities. Industry interactions.

Person N Should identify the weak point of the students and provide feedback to improve them. Then they will be able competitive in the industry better. It will also lead to achieve the sustainable competitive advantage in the higher education institutes. Participation in competitions.

$\begin{array}{lll}\text { Coding } & & \\ \text { Increase } & \text { quality, } & \text { reputation, } \\ \text { Produce } & \text { quality } & \text { graduates. }\end{array}$

Accreditations.

Talent management.
Rankings/Indexing's

Increase reputation for increasing the quality.

Increasing the customer loyalty by maintaining a good relationship with customers.

By producing highly competent graduates to the industry. Theories can use to analyze the current status of the organization and improve the faults.

By improving the institute image. Produce skilled graduates.

Customer loyalty, great location, proper curriculum. By using business intelligence.

Increase reputation and branding.

Using theories such as Porter's competitiveness and resource advantage theories.

Improve the quality of internal staff.

Evaluate challenges and threats.

Analyze the current situation and improve the quality. Recruit quality employees to the organization.

Improve the current status by comparing with competitors. Industry interactions.

Improve the performance of students by identifying the weak points. Participation in competitions. 
List of codes derived from the analysis in relation to the sustainable competitive advantage in Higher Education Institutes are as follows;

- Maintaining good reputation

- Maintaining rankings/ indexings.

- Maintain good relationships with industries

- Student participation in competitions

- Accreditations with reputable institutions

- Growing customer base

- Improve student performance

- Maintaining recognizable name (brand)

- Desirable market position

- Market-oriented curriculum

- Producing quality market ready students

- Risk Management

- Competent faculties including top-level reputable professors.

- Good vendor relations

- Effective international network and rich experiential knowledge.

- International to domestic student ratio.

- Research productivity of the university

- No of degree programs awarded by the Institute

Identified codes summarized according to their importance as follows; Summarization has considered the number of participants who have mentioned the particular code. 


\section{No of Participants}

No of degree programs awarded by.

Research productivity of the university

International to domestic student ratio.

Effective international network and.

Good vendor relations

Competent faculties including top.

Risk Management

Producing quality market ready.

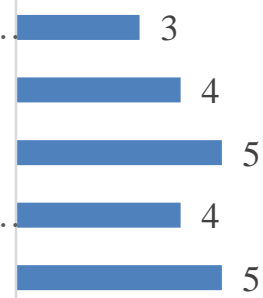

Market oriented curriculum

Desirable market position

Maintaining recognizable name (brand)

Improve student performance

Growing customer base

Accreditations with reputable.

Student participation in competitions

Maintain good relationships with.

Maintaining rankings/indexing's.

Maintaining good reputation

7

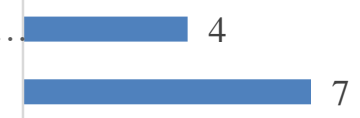

Figure 3. Summary of Open Coding: Factors affecting to the sustainable competitive advantage in higher education

\subsection{Axial Coding: Factors Affecting the Sustainable Competitive Advantage in Higher Education}

To identify the factors affecting the sustainable competitive advantage organizations should identify the key areas that give more competitiveness. Since all the participants are decision makers of the organization, identifying factors is not a difficult task. According to the above analysis, most important elements affect the sustainable competitive advantage, as identified as.

\begin{tabular}{|llr|}
\hline - & Maintaining good reputation & 15 \\
\hline - & Maintaining rankings/ indexings. & 7 \\
- & Maintain good relationships with industries & 4 \\
- & Student participation in competitions & 3 \\
- & Accreditations with reputable institutions & 3 \\
\hline - & Growing customer base & 11 \\
\hline - & Improve student performance & 15 \\
\hline - & Maintaining recognizable name (brand) & 15 \\
\hline - & Desirable market position & 7 \\
\hline - & Market-oriented curriculum & 13 \\
\hline$\bullet$ & Producing quality market ready students & 15 \\
\hline & Risk Management & 3 \\
\hline
\end{tabular}




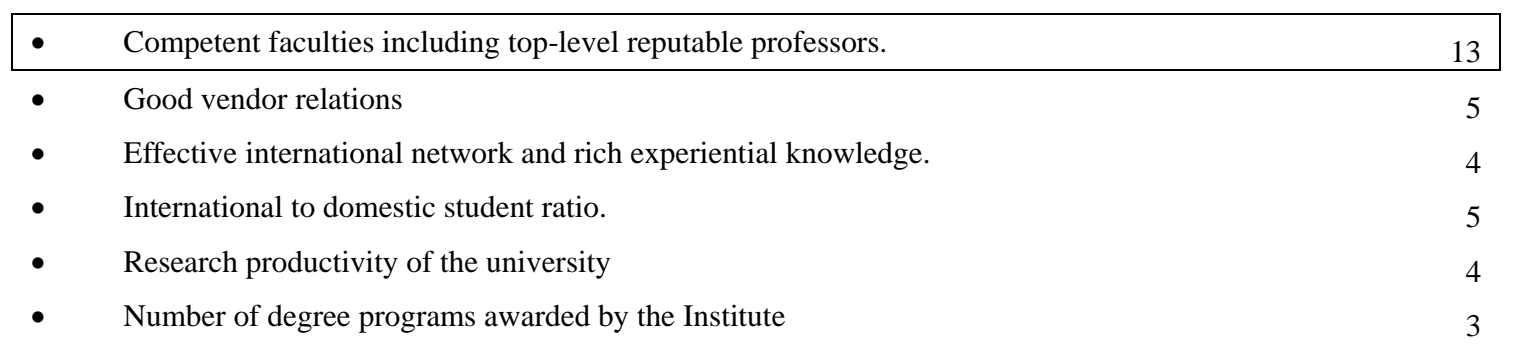

This represents out of the 18 characteristics most important elements to gain the sustainable competitive advantage are maintaining a good reputation, growing customer base, improve student performance, market-oriented curriculum, produce quality market ready students and develop competent faculties with top-level reputable professors. Even though there are only a few elements are more important out of 18, all the others are also can relate to the important themes. As an example to have a good reputation higher education institutions should able to maintain good market-oriented curriculum, and quality market ready students and good performance of the students. Thus axial coding has performed to categories above elements to different themes as below;

To Maintaining Good Reputation higher education institutes should maintain all the below elements.

- Maintaining rankings/ indexings.

- Maintain good relationships with industries

- Student participation in competitions

- Accreditations with reputable institutions

- Growing customer base

- Improve student performance

- $\quad$ Maintaining recognizable name (brand)

- Desirable market position

- Market-oriented curriculum

- $\quad$ Producing quality market ready students

- Risk Management

- Competent faculties including top-level reputable professors.

- Good vendor relations

- $\quad$ Effective international network and rich experiential knowledge.

- International to domestic student ratio.

- Research productivity of the university

- $\quad$ Number of degree programs awarded by the Institute

Thus, it emphasizes even though the other category has less number of votes from the participants, those are also important to have a good reputation. In the same way, to improve student performance, it is necessary to have following subcategories;

- $\quad$ Maintain good relationships with industries

- $\quad$ Student participation in competitions

- Accreditations with reputable institutions

- Improve student performance

- Market-oriented curriculum

- Risk Management

- Competent faculties including top-level reputable professors.

- $\quad$ Effective international network and rich experiential knowledge.

- Research productivity of the university

Another axial code is, "maintain a recognizable brand name". To achieve this advantage, it is necessary to have 
good accreditations and maintaining student performance is highly important.

According to the above-proposed elements, it is not possible to measure factors affecting the sustainable competitive advantage for higher education institutes directly. What we can measure are the usual factors, which lead to the market success of the higher educational institutes.

\subsection{Generating Themes: Identify the Competitive Factors of Higher Education}

\section{Market Profile}

Several unique competencies can be identified as sources which give the sustainable competitive advantage. The main variables that strengthen the sustainable competitive advantage of higher educational institutes are the quality image of the institute or high market profile. To maintain the quality of the image, institutes should maintain the student performance and produce quality graduates to the market. If universities foster and remain in the fields in which they have a competitive advantage, organizations will recruit top students. Once institute maintains the image, the market profile will be automatically coming to a satisfied level or upper level compares to the other competitors.

Currently, most of the students with high profiles are targeting the universities with highest rankings. Institutions that generate university rankings consider, employer review, academic peer review, faculty to student ratio, citations per faculty member, proportion of faculty that are international, and proportion of students that are international, major academic awards to alumni, major academic awards to staff, Weighted count of alumni winning Nobel Prizes or Fields Medals. The research outcomes should map with students rather than the staff. In the current situation, less number of peer review dissertations have led the universities to receive low rankings compared to the international HEI market.

\section{Core competencies}

The organizational expertise and quality staff is also an important element. According to the literature, organizational expertise is a source of a method which can use to achieve competitive advantage. The primary data has also emphasized that students used select courses and institutions due to the reputation of the teaching staff. Further management training and employee training is necessary to improve the Excellency of the staff because the tacit knowledge will lead to reshape the culture of the organization and better management strategies. This importance of the supportive organizational culture has outlined in the literature also when comes to new system implementation. Because then employees will understand the importance of the customer-oriented service and helps to deployed new strategies within the organization. Always organization should have the ability to develop strong core values which leads to innovation and flexibility to maintain superior financial and organizational performance within the organization. When this situation applies to Sri Lankan organizations lacking the above concept, compared to the international organizations. Technological advancements are resistant to the employees.

\section{Business Strategy and Innovation}

The nature of the market success in higher education may change according to one institute to another. According to literature, strategies should align with the porters five forces theory which developed in 1979(Woodruff, 1997). Within educational institutes, mainly two aspects are considering; the threats of new entrants incorporate with corporate universities and virtual universities, bargaining power of students align with more educational options. Both aspects have a direct influence on the strategy and financial results of. Further differentiation offers innovative educational services, distinguishing from its direct competitors.

Above discussion emphasize that the most important aspect of sustainable competitive advantage is an organization to develop strategies which cannot imitate by others. For example, Sri Lankan universities still do not have the capability to attract enough international students due to the less attractiveness and the reputation. According to the literature, "if a university's principal objectives are to develop its international student base, it must focus principally on its architecture, reputation and innovative capability”(Lynch \& Baines, 2004).

Thus, there should be a mechanism to achieve that aspect. Further, those strategies should sustainable in the long term. AA or big data in education is a one way which can achieve this advantage according to the literature.

\section{Service Quality}

To produce market-ready quality students, universities should continuously adapt the innovative curriculum align with the industry requirements. To maintain the standards, the curriculum should align with top international standards as well. The current situation is, even though the course content aligns with the standards, delivery, and marking has not properly aligned. To maintain the retention of the students and attraction, universities have 
ignored the value of the marking standards. Thus this has led to increase the student's satisfaction, but to reduce the service quality.

Currently, Higher education institutions are categorized under service industry, therefore, HEI places greater prominence on student expectations and satisfaction. This has become a more significant factor in the universities which mainly focused on their budget on tuition. The rapid expansion of the universities and colleges, competition, significant increases in college education costs combined with demographic shifts in the population, has led HEI to in different point of view regarding the student satisfaction and retention. Moreover, aggressive competition led HEI to use different marketing strategies to differentiate with competitors.

According to the study of Edwell, the number of insights has recognized in the learning environment such as, transform the student into a flexible thinker, feedback collection to improve the learning effects(Srikanthan \& Dalrymple, 2002). But due to the present situation, the student has become a spoon feeder rather than a self-learner. Students expect to learn everything in the classroom which is in the examination paper. Therefore this has led to lack of systematic thinking, interdependencies within the education. As a result, modules and instructions do not deliver to achieve learning gains. But the long-term outcome is student becomes more loyal by graduating with high knowledge rather than students who appear to be satisfied without complaints. Even though the higher management expecting this outcome from the college, middle management tries to survive with the short-term satisfaction of the students. Past studies consistently state that satisfied customers such as students, parents are the primary goal of higher education(DeShields, Kara, \& Kaynak, 2005). But in this context, this will lead to the dissatisfaction of the long-term student satisfaction and the reputation of the organization. Thus, focusing on enhancing customer satisfaction at colleges and universities is crucial in developing customer value. Therefore this is a significant point to consider when maintaining the quality.

\section{Conclusion}

Understanding the factors affecting the sustainable competitive advantage is a crucial factor for any organization. However, prior research has not investigated this from the perspective of an HEI. Thus, the objective of this research was to identify the factors affecting the Sustainable competitive advantage in HEI.

When considering the research question posed at the outset of this paper, we argued that an HEIs main concern is to grow the customer base. Importantly, our investigation suggests that some HEI resources such as AA are sustainable for a longer period due to the ability to analyze and forecast the future outcomes.

Key outcomes of this research are, maintaining rankings/indexing's, maintain good relationships with industries, student participation in competitions, accreditation with by reputable institutions. Those are some of the vital factors of an HEI with regard to maintaining a sustainable competitive advantage.

Further, in this research, customer-driven approach and feedback centric approach to improving the quality was not approved in the Sri Lankan context due to the negative mindset of the students. Effective management is necessary to achieve this in HEI.

The factors that we identified in this paper have a significant impact to the HEI since they can achieve sustainable competitive advantage, by following the identified factors. Further, this gives valuable insights for the HEI management and marketing department to make decisions. As future research directions, it is necessary to test these factors using large-scale surveys and structural modeling procedures. Further, this method can relate to other service industries in the process of gaining sustainable competitive advantage

\section{References}

Agha, S., Alrubaiee, L., \& Jamhour, M. (2011). Effect of Core Competence on Competitive Advantage and Organizational Performance. International Journal of Business and Management, 7(1), 192-204. https://doi.org/10.5539/ijbm.v7n1p192

Ali, L., Asadi, M., Ga Sevi C, D., Jovanovi, J., \& Hatala, M. (2013). Factors influencing beliefs for adoption of a learning analytics tool: An empirical study. Computers \& Education, 62, 130-148. https://doi.org/10.1016/j.compedu.2012.10.023

Barney, J. (1991). Firm Resources and Sustained Competitive Advantage. Journal of Management, 17(1), 99-120. https://doi.org/10.1177/014920639101700108

DeShields, O. W., Kara, A., \& Kaynak, E. (2005). Determinants of business student satisfaction and retention in higher education: applying Herzberg's two-factor theory. International Journal of Educational Management, 19(2), 128-139. https://doi.org/10.1108/09513540510582426

Dillon, D. (2012). Grounded theory and qualitative research. The Encyclopedia of Applied Linguistics, 1-8. 
https://doi.org/10.1002/9781405198431.wbeal0486

Elo, S., \& Kyngäs, H. (2008). The qualitative content analysis process. Journal of Advanced Nursing, 62(1), 107-115. https://doi.org/10.1111/j.1365-2648.2007.04569.x

Lynch, R., \& Baines, P. (2004). Strategy development in UK higher education: Towards resource-based competitive advantages. Journal of Higher Education Policy and Management, 26(2), 171-187. https://doi.org/10.1080/1360080042000218249

Mazzarol, T., \& Norman Soutar, G. (1999). Sustainable competitive advantage for educational institutions: a suggested model. International Journal of Educational Management, 13(6), 287-300. https://doi.org/10.1108/09513549910294496

Sadler, P. (1993). Strategic Management.

Schläfke, M., Silvi, R., \& Möller, K. (2012a). A framework for business analytics in performance management. International Journal of Productivity and Performance Management, 62(1), 110-122. https://doi.org/10.1108/17410401311285327

Schläfke, M., Silvi, R., \& Möller, K. (2012b). International Journal of Productivity and Performance Management (A framework for business analytics in performance management). International Journal of Productivity and Performance Management, 62(2), 110-122. https://doi.org/10.1108/17410401311285327

Sekaran, U. (2013). Research methods for business. Research methods for business (Vol. 65). John Wiley \& Sons, Ltd. https://doi.org/10.1017/CBO9781107415324.004

Srikanthan, G., \& Dalrymple, J. F. (2002). Developing a Holistic Model for Quality in Higher Education. Quality in Higher Education, 8(3), 215-224. https://doi.org/10.1080/1353832022000031656

Velazquez, L., Munguia, N., \& Sanchez, M. (2005). Deterring sustainability in higher education institutions. International Journal of Sustainability in Higher Education, 6(4), 383-391. https://doi.org/10.1108/14676370510623865

Woodruff, R. B. (1997). Customer value: The next source for competitive advantage. Journal of the Academy of Marketing Science, 25(2), 139-153. https://doi.org/10.1007/BF02894350

Agha, S., Alrubaiee, L., \& Jamhour, M. (2011). Effect of Core Competence on Competitive Advantage and Organizational Performance. International Journal of Business and Management, 7(1), 192-204. https://doi.org/10.5539/ijbm.v7n1p192

Ali, L., Asadi, M., Ga Sevi, C. D., Jovanovi, J., \& Hatala, M. (2013). Factors influencing beliefs for adoption of a learning analytics tool: An empirical study. Computers \& Education, 62, 130-148. https://doi.org/10.1016/j.compedu.2012.10.023

Barney, J. (1991). Firm Resources and Sustained Competitive Advantage. Journal of Management, 17(1), 99-120. https://doi.org/10.1177/014920639101700108

DeShields, O. W., Kara, A., \& Kaynak, E. (2005). Determinants of business student satisfaction and retention in higher education: applying Herzberg's two-factor theory. International Journal of Educational Management, 19(2), 128-139. https://doi.org/10.1108/09513540510582426

Dillon, D. (2012). Grounded theory and qualitative research. The Encyclopedia of Applied Linguistics, 1-8. https://doi.org/10.1002/9781405198431.wbeal0486

Elo, S., \& Kyngäs, H. (2008). The qualitative content analysis process. Journal of Advanced Nursing, 62(1), 107-115. https://doi.org/10.1111/j.1365-2648.2007.04569.x

Lynch, R., \& Baines, P. (2004). Strategy development in UK higher education: Towards resource-based competitive advantages. Journal of Higher Education Policy and Management, 26(2), 171-187. https://doi.org/10.1080/1360080042000218249

Mazzarol, T., \& Norman, S. G. (1999). Sustainable competitive advantage for educational institutions: a suggested model. International Journal of Educational Management, 13(6), 287-300. https://doi.org/10.1108/09513549910294496

Sadler, P. (1993). Strategic Management.

Schläfke, M., Silvi, R., \& Möller, K. (2012a). A framework for business analytics in performance management. International Journal of Productivity and Performance Management, 62(1), 110-122. https://doi.org/10.1108/17410401311285327 
Schläfke, M., Silvi, R., \& Möller, K. (2012b). International Journal of Productivity and Performance Management (A framework for business analytics in performance management). International Journal of Productivity and Performance Management, 62(2), 110-122. https://doi.org/10.1108/17410401311285327

Sekaran, U. (2013). Research methods for business. Research methods for business (Vol. 65). John Wiley \& Sons, Ltd. https://doi.org/10.1017/CBO9781107415324.004

Srikanthan, G., \& Dalrymple, J. F. (2002). Developing a Holistic Model for Quality in Higher Education. Quality in Higher Education, 8(3), 215-224. https://doi.org/10.1080/1353832022000031656

Velazquez, L., Munguia, N., \& Sanchez, M. (2005). Deterring sustainability in higher education institutions. International Journal of Sustainability in Higher Education, 6(4), 383-391. https://doi.org/10.1108/14676370510623865

Woodruff, R. B. (1997). Customer value: The next source for competitive advantage. Journal of the Academy of Marketing Science, 25(2), 139-153. https://doi.org/10.1007/BF02894350

\section{Copyrights}

Copyright for this article is retained by the author(s), with first publication rights granted to the journal.

This is an open-access article distributed under the terms and conditions of the Creative Commons Attribution license (http://creativecommons.org/licenses/by/4.0/). 